\title{
Skin Melanomas Excised by General Practitioners: More Often Unsuspected, of Nodular Type and Less of Often Radically Excised Than Those Excised in an Academic Setting
}

\author{
Pieter AJ Buis ${ }^{1}$, Folkert J van Kemenade ${ }^{2}$, Bernard D Frijling ${ }^{3}$ and Paulus Joannes van Diest ${ }^{4 *}$
}

${ }^{1}$ General Practice H. de Manstraat, Harderwijk, Netherlands

${ }^{2}$ Department of Pathology, VU University Medical Center, Amsterdam, Netherlands

${ }^{3}$ Diagnostic Centre Saltro, Utrecht, Netherlands

${ }^{4}$ University Medical Center Utrecht, Utrecht, Netherlands

\section{Background}

In The Netherlands, the incidence of cutaneous melanoma is about 3000 per year in a population of about 16 million. It is expected that by 2015, the incidence of melanoma in The Netherlands will have increased by $99 \%$ compared to 2005 [1]. Since the prognosis of melanoma is strictly related to Breslow thickness with a five years survival of $85-98 \%$ in case of a thickness $<0.75 \mathrm{~mm} 95-98 \%$ compared to $45 \%$ for thickness $>1.5 \mathrm{~mm}$, detection and primary radical removal in the earliest possible stage is essential.

Since the majority of pigmented skin lesions presents at the GP, adequate clinical diagnosis by GPs is crucial. GPs can then do a narrow excision in the majority of patients with smaller lesions with a low index of suspicion in uncomplicated body areas, while referring patients with high index of suspicion lesions to a dermatologist or surgeon, as well as refer those that provide technical problems because of bigger size or the anatomic location.

Melanomas usually present as an irregular pigmented lesion of varying size, but presentation may be atypical. Based on clinical assessment, the general practitioner (GP) decides to reassure the patient, excise the lesion himself or refer the patient to a hospital. The latter will especially occur in case of a high index of suspicion, but also for larger lesions and lesions on body parts that will cause technical or cosmetic problems for the GP such as hands, feet or face. However, previous studies have shown that clinical diagnosis of pigmented skin lesions by GPs is not very accurate [2-7]. Our own studies [3,4] showed that $1.9 \%$ of pigmented skin lesions submitted for histopathology bared a (pre) malignancy, $62 \%$ of the malignancies being an unsuspected melanoma. Although it has not convincingly been proven that (incisional) biopsies of melanomas worsen prognosis [8], best practice for a GP is yet to radically excise suspicious lesions whenever possible or refer to a dermatologist or surgeon. Therefore, proper assessment of the index of suspicion by GPs would result in optimal care for patients with pigmented lesions: primary excision followed by sentinel node biopsy if indicated for patients with a high index of suspicion by dedicated specialists (surgeons or dermatologists), and narrow excision with good cosmetic outcome by GPs of lesions with a low index of suspicion.

We undertook the present study where we compared melanomas excised by GPs with those excised by dermatologists and surgeons in an academic practice to identify several differences between the two groups of melanomas that may be translated into better clinical practice of GPs.

\section{Methods}

The Pathology database of the Saltro, a general practitioner's diagnostic centre in the Utrecht region, The Netherlands, was retrospectively searched for skin excisions with the diagnosis "melanoma" in the years 1995-2006. During these years, dermatoscopy

was not yet applied. These diagnoses had been made at the Department of Pathology of the VU University Medical Center in Amsterdam. This yielded 188 cases of "GP melanomas". For each patient, sex, clinical diagnosis, melanoma type, Clark level, Breslow thickness, and radicality of the excision were noted. From the pathology database of the Department of Pathology of the University Medical Center Utrecht, the first 10 primary skin "academic" melanomas were selected from each year within the same period, resulting in 120 cases. Five cases appeared to be referrals, leaving 115 representative "academic" melanoma cases.

Differences between the GP and academic melanomas were analyzed by t-test for continuous and chi-square statistics for discrete individual features. Logistic regression analysis was performed to identify independent discriminative features. All statistics were done with SPSS (version 15.0).

\section{Results}

Table 1 shows the results of the comparison of clinicopathologic features between GP and academic skin melanomas. Melanomas excised by GPs were significantly more often located on trunk and extremities $(\mathrm{p}<0.0001)$ while academic melanomas were more frequently located in the head\&neck, hand/feet and face regions. Further, the GP melanoma cases concerned significantly more often females $(\mathrm{p}=0.006)$. Also the melanoma subtype differed: GP melanomas were more frequently of nodular type $(\mathrm{p}<0.0001)$. Moreover, Clark level III occurred more frequently in GP melanomas $(\mathrm{p}<0.0001)$. Lastly, melanomas excised by GPs were significantly less often radically removed $(\mathrm{p}<0.0001)$. Age and Breslow thickness were not significantly different. In logistic regression, localization, melanoma subtype and sex emerged as independent discriminative variables. In the subgroup of cases without the clinical diagnosis melanoma (85.5\%), similar trends were seen (data not shown).

Clinical diagnosis of melanoma was most often nevocellular nevus by GP $(63.5 \%)$ and melanoma by the academics $(45.2 \%)(\mathrm{p}<0.0001)$ Only $14.4 \%$ of GP melanomas were clinically suspected while $45 \%$ of academic melanomas were clinically suspected to be one $(\mathrm{p}<0.0001)$.

${ }^{*}$ Corresponding author: Paulus Joannes van Diest, University Medical Cente Utrecht, Utrecht, Netherlands, E-mail: p.j.vandiest@umcutrecht.nl

Received June 24, 2011; Accepted July 18, 2011; Published July 22, 2011

Citation: Buis PAJ, van Kemenade FJ, Frijling BD, van Diest PJ (2011) Skin Melanomas Excised by General Practitioners: More Often Unsuspected, of Nodula Type and Less of Often Radically Excised Than Those Excised in an Academic Setting. J Clin Exp Dermatol Res 2:125. doi:10.4172/2155-9554.1000125

Copyright: ( 2011 van Diest PJ, et al. This is an open-access article distributed under the terms of the Creative Commons Attribution License, which permits unrestricted use, distribution, and reproduction in any medium, provided the original author and source are credited. 
Citation: Buis PAJ, van Kemenade FJ, Frijling BD, van Diest PJ (2011) Skin Melanomas Excised by General Practitioners: More Often Unsuspected of Nodular Type and Less of Often Radically Excised Than Those Excised in an Academic Setting. J Clin Exp Dermatol Res 2:125. doi:10.4172/2155-9554.1000125

\begin{tabular}{|c|c|c|c|c|}
\hline & & $\begin{array}{l}\text { GP melanomas } \\
\mathrm{N}=188\end{array}$ & $\begin{array}{l}\text { Academic } \\
\text { melanomas } \\
\mathrm{N}=115\end{array}$ & $p$-value \\
\hline Age & $\begin{array}{l}\text { Mean in years } \\
\text { (range) }\end{array}$ & 47 (7-94) & $51(10-93)$ & $0.060^{*}$ \\
\hline \multirow[t]{2}{*}{ Sex } & Male & $68(36 \%)$ & $60(52 \%)$ & 0.004 \\
\hline & Female & $120(64 \%)$ & $55(48 \%)$ & \\
\hline \multirow[t]{6}{*}{$\begin{array}{l}\text { Clinical } \\
\text { diagnosis }\end{array}$} & Nevocellular nevus & $119(63.5 \%)$ & $44(38.3 \%)$ & $<0.0001$ \\
\hline & Fibroma & $10(5.3 \%)$ & $1(0.9)$ & \\
\hline & Wart & $4(2.1 \%)$ & $0(0 \%)$ & \\
\hline & $\begin{array}{l}\text { Seborrhoic } \\
\text { keratosis }\end{array}$ & $7(3.7 \%)$ & $4(3.5)$ & \\
\hline & Melanoma & $27(14.4 \%)$ & $52(45.2 \%)$ & \\
\hline & No diagnosis & $12(6.4 \%)$ & $13(11.3 \%)$ & \\
\hline \multirow[t]{5}{*}{ Localisation } & Head/neck & $2(1.1 \%)$ & $8(7.0 \%)$ & $<0.0001$ \\
\hline & Extremities & $108(57.1 \%)$ & $46(40.4)$ & \\
\hline & Trunk & $69(36.5 \%)$ & $44(38.6 \%)$ & \\
\hline & Hand/feet & $5(2.6 \%)$ & $6(5.3 \%)$ & \\
\hline & Face & $1(0.5 \%)$ & $10(8.8 \%)$ & \\
\hline \multirow[t]{6}{*}{ Type } & In situ & $9(4.8 \%)$ & $2(1.7 \%)$ & $<0.0001$ \\
\hline & $\begin{array}{l}\text { Superficial } \\
\text { spreading }\end{array}$ & $126(67 \%)$ & $84(73 \%)$ & \\
\hline & Nodular & $51(27 \%)$ & $15(13 \%)$ & \\
\hline & Lentigo malignant & 0 & $8(7.0 \%)$ & \\
\hline & Acrolentiginous & 0 & $3(2.6 \%)$ & \\
\hline & Spindle cell & $1(0.5 \%)$ & $2(1.7 \%)$ & \\
\hline Breslow & $\begin{array}{l}\text { Mean in } \mathrm{mm} \\
\text { (range) }\end{array}$ & $1.51(0-6.9)$ & $1.80(0-10)$ & $0.196^{*}$ \\
\hline \multirow[t]{5}{*}{ Clark level } & I & $12(6.3 \%)$ & $8(7.0 \%)$ & $<0.0001$ \\
\hline & II & $58(30.7 \%)$ & $34(29.6 \%)$ & \\
\hline & III & $94(49.7 \%)$ & $27(23.5 \%)$ & \\
\hline & IV & $24(12.7 \%)$ & $43(37.4 \%)$ & \\
\hline & V & $1(0.5 \%)$ & $3(2.6 \%)$ & \\
\hline \multirow[t]{2}{*}{ Radical excision } & Yes & $101(56.7 \%)$ & $89(87.3 \%)$ & $<0.0001$ \\
\hline & No & 77 (43.3\%) & $13(12.7)$ & \\
\hline
\end{tabular}

Table 1: Comparison of clinicopathologic features between melanomas excised by general practitioners (GP) and by academic specialists ( $p$-value by chi-square statistics except * by t-test). Unknown cases are not listed.

Table 2 shows the clinical diagnoses of the subgroup of nodular melanomas excised in an academic setting and by GPs. While $60 \%$ of the academic nodular melanomas were clinically diagnosed as melanoma, only $5.9 \%$ of the GP nodular melanomas were clinically diagnosed as such. While the clinical diagnoses of nodular melanomas missed in the academic setting were more spread over the categories "nevi" (13.3\%), "fibroma" (6.7) and "granuloma" (6.7\%), nodular melanomas missed by GPs were most often considered to be nevi $(47 \%)$ of fibromas $(11.8 \%)$.

\section{Discussion}

To identify which features characterize melanomas excised by GPs, we compared melanomas excised by GPs with those excised by dermatologists and surgeons in an academic practice. Skin melanomas excised by GPs were more often located on trunk and extremities found in females, of nodular type and Clark level III, and were less often radically removed.

Clinical differential diagnosis included melanoma in 14\% of GP melanomas and $45 \%$ of academic melanomas. Of the GP melanomas, $64 \%$ was clinically considered to be a benign nevus in contrast with $38 \%$ of academic melanomas. This does not necessarily mean that GPs do worse in diagnosing melanoma, since GPs will usually refer patients with highly suspicious lesions anyway, and the low index of suspicion lesions will be treated by the GPs.

The more frequent under diagnosis of melanomas by GPs is likely in part the reason that there were fewer radical excisions by GPs compared to the academic specialists, the latter at variance with a previous study [9]. A low index of suspicion will usually lead to a narrow primary excision with a higher risk of irradicality. Although some studies suggest that a primary irradical excision may not influence prognosis $[10,11]$, the general consensus is to refer pigmented lesions with a high index of suspicion to a dermatologist or surgeon for a slightly wider local excision followed by re-excision and sentinel node biopsy $[12,13]$ if indicated. The very fact that such patients are referred leads to an enriched "suspicious" population of lesions for which the academic specialists would inherently more often do more a slightly wider local excision, could also contribute to the higher rate of academic radical excisions. Indeed, the clinical diagnosis in melanoma cases was also melanoma in $45 \%$ of academic cases, while this was only $14 \%$ for GPs. Quite likely, at least part of these patients were referred because the GP already suspected a melanoma.

GP melanomas concerned remarkably more often women, for which we have no obvious explanation. Although this could be assumed to be confounded by site, our logistic regression made this unlikely. Women may prefer going to GPs while men prefer hospital treatment, indicating that patients may be driving excisions, or men may be more easily referred than women by GPs themselves. Although it cannot be excluded that melanomas in women are more easily under diagnosed, we can only speculate why.

Further, GP melanomas were more frequently of nodular type, which is a significant finding, in line with a previous study [14]. Nodular melanomas have a vertical rather growth pattern than the primarily horizontal growth pattern of superficial spreading melanomas. Nodular melanomas therefore present with higher Breslow thickness and Clark level, which may explain the finding of more Clark level III lesions in the GP group in the present study. Apparently, nodular melanomas are frequently under diagnosed by GPs as they disguise as benign nevus or may not be pigmented at all and mimick lesions fibroma (Table 2).

A potential confounder in this study is that we have no reliable data whether clinically benign lesions may have been excised for cosmetic/ functional purposes. Nodular benign appearing lesions may have been excised for this reason, so we cannot with certainty state that nodular melanomas are more often misdiagnosed than superficial spreading melanomas if these would not be excised and therefore not detected. Nevertheless, because of the different grow patterns of nodular (vertical) and superficial spreading melanoma (horizontal) with its associated differences in prognosis, we feel it is important to bring the message of missing nodular melanomas by GPs. Growing awareness will contribute to earlier detection and thereby less deep growing (and thus prognostically more favorable) nodular melanomas.

Skin melanomas excised by GPs were significantly more often located on trunk and extremities while academic melanomas were more frequently located in the head\&neck, hand/feet and face regions. This was an expected finding, since pigmented lesions in these latter regions will usually for technical reasons be referred to a dermatologist or surgeon irrespective of the index of suspicion.

These findings may be translated into more specific training of GPs with more specific focus on these features. Further, the gradual introduction of dermatoscopy in general practice may help here as suggested in several studies $[15,16]$. 
Citation: Buis PAJ, van Kemenade FJ, Frijling BD, van Diest PJ (2011) Skin Melanomas Excised by General Practitioners: More Often Unsuspected of Nodular Type and Less of Often Radically Excised Than Those Excised in an Academic Setting. J Clin Exp Dermatol Res 2:125. doi:10.4172/2155-9554.1000125

Page 3 of 3

\begin{tabular}{|l|l|l|l|l|l|l|l|l|}
\hline & Nevus & Fibroma & Seborrhoic keratosis & Melanoma & Granuloma & Wart & Basocellular carcinoma & Cyst \\
\hline Academic cases & $2(13.3 \%)$ & $1(6.7 \%)$ & $1(6.7 \%)$ & $9(60 \%)$ & $1(6.7 \%)$ & 0 & 0 \\
\hline GP cases & $24(47 \%)$ & $6(11.8 \%)$ & $3(5.9 \%)$ & $3(5.9 \%)$ & $5(9.8 \%)$ & $2(3.9 \%)$ & $1(2.0 \%$ \\
\hline
\end{tabular}

Table 2: Clinical diagnoses of skin lesions bearing nodular melanomas excised in an academic setting and by GPs (cases with unknown clinical diagnosis not listed).

One issue is to which extent the study populations are representative for GP and academic melanomas. The GP melanomas were derived from a period of 12 years in which about 50,000 skin excisions were submitted for pathology by a group of about $600 \mathrm{GPs}$, spread over both urban and rural areas in the center of The Netherlands. We therefore feel that the study population of GP melanomas is likely representative for The Netherlands. Academic melanomas were selected from the same years to compensate for stage migration, and there are few reasons to assume that melanomas excised in the UMCU academic setting (not a reference center for familial melanoma patients) are different from those excised in other academic hospitals or even regional hospitals. Both study populations were diagnosed in academic pathology labs with melanoma a specialist, which makes it unlikely that different diagnostic criteria have led to the differences in the two study populations.

Although our data are from the pre-dermatooscopy era, they are likely still valid since dermatoscopy is in its infancy in general practice and certainly not yet the gold standard in The Netherlands and probably many other western European countries. This is related to the fact that dermatoscopy has not been proven to improve diagnosis for untrained or less experienced examiners, which applies to most GPs [17].

In conclusion, GPs seem to limit themselves to excising melanomas from the trunk and extremities. GPs remove more unsuspected skin melanomas, melanomas in women, and more nodular type melanomas than academic specialists. This indicates that especially nodular type melanomas (that are thicker and have in general a worse prognosis) are under diagnosed by GPs. This under diagnosing seems to result in too narrow margins on excision, leading to a lower proportion of radical excisions. Future studies will reveal to which extent dermatoscopy is useful here.

\section{References}

1. Van der Sanden GA, Coebergh JW, Schouten LJ, Visser O, van Leeuwen FE (1995) Cancer incidence in The Netherlands in 1989 and 1990: first results of the nationwide Netherlands cancer registry. Coordinating Committee for Regional Cancer Registries. Eur J Cancer 31A(11): 1822-1829.

2. Eulderink $F$ (1994) How accurate is the clinical diagnosis in skin tumors removed by the family physician, surgeon or dermatologist? Ned Tijdschr Geneeskd 138: 1618-1622.

3. Buis PAJ, Chorus R, Van Diest PJ (2005) Value of histopathologic analysis of skin excisions by general practitioners. Br J Gen Pract 55: 458-460.

4. Buis PAJ, Verweij W, Van Diest PJ (2007) Value of histopathologic analysis of subcutis excisions by general practitioners. BMC Family Practice 8: 5.

5. Heal CF, Raasch BA, Buettner PG, Weedon D (2008) Accuracy of clinical diagnosis of skin lesions. $\mathrm{Br} \mathrm{J}$ Dermatol 159: 661-668.

6. Chen SC, Bravata DM, Weil E, Olkin I (2001) A comparison of dermatologists' and primary care physicians' accuracy in diagnosing melanoma: a systematic review. Arch Dermatol 137: 1627-1634.

7. Khorshid SM, Pinney E, Bishop JA (1998) Melanoma excision by general practitioners in north-east Thames region, England. Br J Dermatol 138: 412417.

8. Molenkamp BG, Sluijter BJ, Oosterhof B, Meijer S, van Leeuwen PA. (2007) Non-radical diagnostic biopsies do not negatively influence melanoma patient survival. Ann Surg Oncol 14: 1424-1430.

9. Neal RD, Cannings-John R, Hood K, Sowden J, Lawrence H, et al. (2008) Excision of malignant melanomas in North Wales: effect of location and surgeon on time to diagnosis and quality of excision. Fam Pract 25: 221-227.
10. Bong JL, Herd RM, Hunter JA (2002) Incisional biopsy and melanoma prognosis. J Am Acad Dermatol 46: 690-694.

11. Molenkamp BG, Sluijter BJ, Oosterhof B, Meijer S, van Leeuwen PA (2007) Non radical diagnostic biopsies do not negatively influence melanoma patient survival. Ann Surg Oncol 14: 1424-1430.

12. Statius Muller MG, van Leeuwen PA, van Diest PJ, Vuylsteke RJ, Pijpers R, et al. (2001) No indication for performing sentinel node biopsy in melanoma patients with a Breslow thickness of less than $0.9 \mathrm{~mm}$. Melanoma Res 11 : 303-307.

13. Statius Muller MG, van Leeuwen PA, de Lange-De Klerk ES, van Diest PJ Pijpers R, et al. (2001) The sentinel lymph node status is an important factor for predicting clinical outcome in patients with Stage I or II cutaneous melanoma. Cancer 91: 2401-2408.

14. McKenna DB, Marioni JC, Lee RJ, Prescott RJ, Doherty VR (2004) A comparison of dermatologists', surgeons' and general practitioners' surgical management of cutaneous melanoma. Br J Dermatol 151: 636-644.

15. Argenziano G, Puig S, Zalaudek I, Sera F, Corona R, et al. (2006) Dermoscopy improves accuracy of primary care physicians to triage lesions suggestive of skin cancer. J Clin Oncol 24: 1877-1882.

16. Westerhoff K, McCarthy WH, Menzies SW (2000) Increase in the sensitivity for melanoma diagnosis by primary care physicians using skin surface microscopy. Br J Dermatol 143: 1016-1020.

17. Kittler H, Pehamberger H, Wolff K, Binder M (2002) Diagnostic accuracy of dermoscopy. Lancet Oncol 3:159-165.

Submit your next manuscript and get advantages of OMICS Group submissions

Unique features:

- User friendly/feasible website-translation of your paper to 50 world's leading languages

- Audio Version of published paper

Digital articles to share and explore

Special features:

100 Open Access Journals

10,000 editorial team

21 days rapid review process

- Quality and quick editorial, review and publication processing

- Indexing at PubMed (partial), Scopus, DOAJ, EBSCO, Index Copernicus and Google Scholar etc

- Sharing Option: Social Networking Enabled

- Authors, Reviewers and Editors rewarded with online Scientific Credits

- Better discount for your subsequent articles

Submit your manuscript at: www.editorialmanager.com/clinicalgroup 